\title{
Study on the Taste-oriented Design of Ceramic Doll in Foshan City
}

\author{
Huanchen Huang \\ South China Normal University, Nanhai District, Foshan City 510631, Guangdong Province, China. \\ Funding: 2015 Foshan Social Science Project(No. QN19 2015). \\ About the Author: Huanchen Huang, 1982-, master, lecturer of Urban Culture College, South China Normal University.
}

\begin{abstract}
Foshan city of Guangdong province, who enjoys the reputation of Ceramics' Capital in South China is one of the largest and most important ceramic production bases in China. Foshan ceramic works of art have a long history and have a great influence in the whole country. In this paper, we try to change the design of the simple historical figure, zodiac animal image and vase purely for daily necessities. To enrich the theoretical results of Foshan ceramic doll art research, Foshan ceramic doll insists taste-oriented design so as to further strengthen the research of interesting design, better adapt to the psychological needs of the audience, create the popular literary and artistic works, lead to the improvement of people's consuming taste, and finally promote the construction of social spiritual civilization and the development of cultural industry in Foshan.
\end{abstract}

Key words: Foshan City; Ceramic Doll; Taste-oriented Design

Publication date: April, 2021; Publication online: 30 April, 2021

*Corresponding author: Huanchen Huang, 20041218@m.scnu.edu.cn

\section{Fundamental Shape of Foshan's Ceramic \\ Doll}

Fast-paced modern life, science and technology have brought people the convenience and comfort of modern life. However, some people are in a state of depression for a long time due to the acceleration of our pace of live. In the need of relaxing environment and pleasant interaction, we are now in pursuit of a simple, cozy, relaxing lifestyle. Especially in the ordinary daily life, how to change the original design style of material and spiritual life supplies that can retain the original characteristics of the original living supplies, but also to keep up with the needs of modern people's ideological mood through deep processing of thinking is worth thinking.

In the perspective of Foshan, ceramic dolls as a representative of Foshan's distinctive brand have gained rapid development in the early years. At that time, many merchants come to Foshan specifically to buy these characteristic ceramic dolls for sale or as a gift. Purchases and sales were booming at the same time. However, in recent years, ceramic dolls in the overall sales have shown a slow growth. According to the field investigation on ceramic doll bases of design and sales such as Shiwan ceramic factory, 1506 cultural and creative industrial park, Nanfeng ancient stove, we found that the existing style of ceramic dolls sold in the market still use the early single design of zodiac animal image, vases for dialy supplies and pure history figure like the poet Quyuan, ChungKue ${ }^{1}$, the duke Guan, Bodhidharma. In short, the design lacks the need of modern people. It can be seen that the ceramic doll in the overall design of the innovation ability has been insufficient and they did not keep up with the pace of development of the times.

From the current situation of social life, it is precisely because the faster and faster pace of life in modern society that make people's body and mind in a state of long-term tension. Therefore, in the various compositions of modern life, the requirements of the interesting design of living objects are greatly in need. Living objects are things that can be shown in front of people every day at any time, taste-orienteddesign is conducive to ease the pressure of people's daily life, at the

1 Chinese celestial being who can ward off bad luck and disaster 
same time can gradually improve people's taste in appreciation. Therefore, they are greatly welcomed. In the design, we can put aesthetic needs of life of the target audience in the design so that ceramic dolls in the primary design the requirements of product interest can be taken into account. According to such design ideas, ceramic dolls can not only in line with people's material needs, but also meet the psychological and spiritual needs of the masses. This kind of taste-oriented design into which "human" thought is put will also become a new meaningful design direction.

\section{The Origination and Manifestation Pattern of Foshan Ceramic Doll}

As far as Foshan ceramic art works are concerned, most of what we see now are the works passed down from the Qing Dynasty, but from the aesthetic point of view, the current Foshan ceramic dolls are mainly inherited from the mid-Qing Dynasty art style, but also absorbed the artistic style of Jiangnan painting school in the late Qing Dynasty and folk art in the Republic of China. The development of Shiwan ceramic art and its dolls, whether in the shape or portrayal, have its distinct artistic characteristics. For the inheritance and development of ceramic doll art production, it can be analyzed by following aspects. First, since the Ming Dynasty, Foshan ceramic doll began to imitate the craft and design of other large ceramic workshops. Although it now seems to be regarded as copycat products, at that time, it did lay the foundation of Foshan ceramic's market expansion. Second, what Foshan produces is clay rather than porcelain soil and it can't compete with other local porcelain bases like Jingdezhen. Therefore, Foshan's craftsman decided to make the best use of local material in the process of production design and focused only on ceramics made of local clay. Third, Lingnan culture and Central Plains culture differ from each other. Different from ceramic craft products in Central Plains, Foshan has given full play to the unique characteristics of Lingnan culture in ceramics design. It emphasized decorative function in the design of ceramic utensils, gradually forming the unique style of Shiwan ceramic dolls furnishing desks. Fourth, due to the continuous efforts of the early artists represented by Huang Qi, Huang Guzhen, etc., the design

${ }^{2}$ Liu Menghan, Shiwan Ceramic Dolls , Guangdong People's Publishing House, P47,October 2006. style of Shiwan ceramic dolls gradually formed. According to the Taiwanese scholar $\mathrm{Wu}$ Jeannon, $\mathrm{Xu}$ Beihong(a famous Chinese painter) has said, "The northern porcelain is white, thin, tender, like a woman's softness, while Shiwan ceramics contain male roughness and masculiity."2

In my opinion, the reason why Shiwan ceramic doll can get the favor of famous painter like $\mathrm{Xu}$ Beihong is that Shiwan ceramic dolls are very vivid and expressive. In order to design the figure, animals or other vivid artistic works of Shiwan ceramic dolls, the creators discover and observe everything in the surrounding during their daily life. Furthermore, they consult older generation engaged in Foshan ceramic doll creation and the masses with the open mind on the one hand, but also deeply study the essence of Chinese culture and Lingnan culture from ancient scholars and then on this basis polish Shiwan ceramic dolls on the other hand.

\section{The Development Course of Foshan Ceramic}

\section{Doll}

On the whole, the design of current home-produced ceramic dolls tend to be traditional. Since most people are not clear about what is taste-oriented design, they think ceramic dolls are nothing but something small to watch. However, Shiwan ceramic dolls have their own unique characteristics. The first feature of Shiwan ceramic dolls is the vivid design. No matter the characters, animals or utensils are of typical shape with a variety of unique styles to achieve the goal of its uniqueness. The second characteristic is the thick glaze layer of the ceramic surface. At present, there are nearly 100 kinds of glaze colors that enrich the aesthetic perception of Shiwan ceramic dolls. The third trait of Shiwan ceramic dolls is the variety of its techniques which can be divided into modeling techniques, product glaze technology and other creative techniques in different aspects. With a long history of thousands of years, Shiwan ceramic doll hass high historical value, scientific value and artistic value. Known as the Oriental Art Pearl, it plays an irreplaceable role in the history of Chinese ceramic art. ${ }^{3}$

In addition to form, color also plays an important role in the taste-and-interest oriented design of Foshan ceramic dolls. For color itself, it has the attribute of arousing people's emotion. But for the object itself, the meaning of color in it

3 Zhong Rurong, Shi Xin, Shiwan's Ceramic Dolls , Guangdong Education Press, October P4,2008. 
can not be expressed by many non-color design components. The correct collocation of color and pottery shape can fully contrast the overall meaning of ceramic dolls. In the design, it is proposed to decorate the works of art properly concisely and applicably. Only in this way can we not focus on the design of the works of art and ignore the works themselves. However, the proper decoration and the expression of interest, whether in terms of the art work itself, the artist's ideological performance, or from the field of thinking of the artistic audience, can achieve the ideological resonance with each other in the expression of art, which will not affect the aesthetic feeling of the works of art, but can increase the interesting performance of the works of art or products.And for the works of art itself, the expression of the form can also reflect the individual interest and practical needs, making the performance of the works of art more distinctive.

At present, for the design of ceramic dolls, some artists will pay more attention to the material, texture, pattern, decoration and so on of ceramic art so as to add some interesting ideas in their design. design. Then, different creative and interesting shapes are made according to different characteristics. Through this special "abnormal" performance, artists hope to achieve a peculiar and interesting aesthetic sense for the art audience, thus forming a bridge between the artist and the art audience. These ceramic designers combine the traditional art form with the modern art style in their artistic creation, forming a new art existence with unique artistic characteristics, transform the traits of the original ceramic material and concrete requirements of design into a changeable and concise modern art style. Although the overall modeling performance is different from the traditional one, it has opened up a new way to the design of taste-and interest oriented design. The coexistence of this creativity and tradition reflects the inheritance and development of Foshan ceramic culture, which is of great guiding significance to the research of Foshan ceramic doll's taste-and -interestoriented design. At the same time, this kind of art works combined with general public opinion can better coincided exactly with art audience. And this kind of coincidence also will inevitably make Foshan ceramic doll to be welcomed by the public.

\section{Outlook on the Taste-oriented Design of Foshan Ceramic Dolls}

In this era of big Internet+ and big data, the adherence to culture and its revolution are worthy of our reflection. Shiwan ceramic doll works of art are also facing new opportunities and challenges. In order to create new brilliance in this new era, we need to make a commitment in a common effort. As for me, the outlook on Foshan ceramic dolls can be elaborated in the following aspects. First, we should renew our ideas. With the pace of modern life getting faster and faster, people generally feel more and more tired. in many places we can see some so-called "lan" culture, "su "culture (or" leisure culture "), which reflects a state of life that modern people hope to pursue themselves. The popularity of ancient town tourism and the increasing number of people at home when they're not at work are also an indirect reflection. Second, we should retain tradition. It is a mistake in the direction that the renewal concept reflect nothing of the essence of the original ceramic doll art. The reform have to be made on the basis of tradition, no one can change directly to "everyone " without the foundation, tradition. Newton has said," If I have seen further, it is by standing on the shoulders of giants." in the same way, like a river, tradition is the source, there is no source of trickle where there will be waves into the sea; Third, we should deeply reform the design ideas. It is necessary to study the taste-oriented design of Shiwan ceramic doll in an inclusive way. We should not only study tradition, but also learn advanced experience from foreign countries. We should vigorously promote artistic diversity, subject matter diversity, modeling performance, design's interest. To carry forward the team spirit, advocate the collective tackling of key problems, we have to actively explore and create a phenomenon that all artists are engaged in the art design and research of Shiwan ceramic dolls and put forward a new idea of "everyone in Shiwan, devotes themselves in the inheritance and development of Shiwan ceramic dolls all over the world ". Furthermore, we need to broaden the design ideas, create a new design environment, improve the social atmosphere of Shiwan ceramic dolls art design and research. Fourth, Shiwan ceramic doll's need to take both taste-oriented design and diversity into account. At present, many ceramic dolls in the market are similar and repetitive products. Most of the design of ceramic dolls still are stagnating in the traditional product design model. They are unable to keep up with the needs of the times and meet the requirements of contemporary development of public art, lacking innovation ability in the ceramic doll design on the whole. Although the image of these ceramic dolls is popular, it seems to be out of date compared with many cartoon fashion. From the perspective of movies, cartoons and children's toys in recent years, we can be found that "Winnie Bear", "Pleasant Goat", "Big Big 
Wolf", "Spider-Man", "Optimus Prime", "Baymax" and other cartoon characters have a high market share. As a Foshan ceramic doll which can create a cartoon and lovely image in expression, it is worth regretting that under the condition and ability, these new and popular cartoon characters have not been included in Foshan ceramic doll, nor have they designed and new and lovely artistic cartoons.

In fact, Foshan's ceramic doll's art design and modeling is not completely static but constantly changing and developing. No change, no development. Through the connection between the present and the future, the tradition of Foshan ceramic doll's artistic design concept is connected to the present, and then merged with culture in the modern era, which determines and affects the development of the future artistic concept. We are still quite pleased to see that some art researchers of the present young generation of Foshan ceramic dolls have realized the importance of the connection between traditional culture and contemporary culture. Realizing the importance of pursuing taste in the artistic modeling of Foshan ceramic dolls, traditional design form of Foshan ceramic dolls should be combined with modern cultural thoughts on the basis of the traditional modeling and the various popular cultures in the society. Designers are breaking through the tradition, forming a new artistic image of the new Foshan ceramic dolls with both the tradition and the fun of the times. However, only the pace of this kind of change and development is still relatively slow and involuntary. And the design consensus of Foshan ceramic dolls and consistent action have not yet formed. It is imperative to adapt to the momentum of the development of modern society and speed up this change and development.

\section{Conclusion}

Foshan ceramic doll culture pass down from generation to generation for thousands of years, forming the unique design style of Guangdong region. This kind of ceramic culture is not only the inheritance and promotion of the original and classical ceramic art, but also the result of combination between the needs of modern ceramic art and modern daily life. When taste-oriented design of modern features is embedded into the current ceramic, the original expression form of Foshan ceramic dolls will be combined with the life notion and artistic idea of modern life. This innovative and taste-oriented design with popular aesthetic characteristics can not only make the original works of art more unique in design, but also bring out a group of ceramic designers deft at modern life design.
Although the times are constantly changing and developing and the shape of ceramic doll has changed, people's feeling on original artistic has not disappeared, which is one of the reasons that determines the sustainable development of ceramic doll art. But the question at this stage is, with the development of science and technology and the further improvement of the aesthetic interest requirements of the people, is it the only way to pay attention to the traditional artistic expression as before? When people pursue the higher spiritual aesthetic demand of art, does art itself bring a relaxed and pleasant feeling to the artistic audience? Do people also feel the atmosphere of taste-oriented art works when they are aesthetically observing those works? The same is true for Foshan ceramic dolls. The relaxed and pleasant artistic feeling can bring the artistic audience a higher level of beauty enjoyment. The artistic taste-oriented design of Foshan ceramic doll's add new elements of modern life while adhering to the original art materials. In this way, the situation of relative monotonousness of original artistic modeling and performance of can be changed and new ideas of modern society can be added. In order to achieve that, some cartoon figures, interesting characters and lovely artistic image should embed in Foshan ceramic dolls. In the tradition strive to innovate, designers are supposed to create a new, modern, and taste-oriented art works that in line with young people's aesthetic in the new era. As for the pattern of manifestation of ceramic doll works, we have to strive for taste-oriented functional, decorative development. If ceramic dolls are strongly based on the local culture with Foshan characteristics, I believe that the new works will inevitably get the attention and love of people in the new period.

From the perspective of culture and creativity, the tasteoriented ceramic dolls should firstly combined with traditional technology to make the ceramic dolls more interesting and playful, and then use marketing pattern to optimize and integrate resource so that the audience can play while appreciating and have design feedback while playing, which indeed is a meaningful activity. Therefore, artists engaged in the study of ceramic doll art design should also deeply realize this point, and combine the spirit of the times, the feelings of the times with the traditional ceramic doll culture. In this process, Foshan ceramic doll art in the new era strive to show new ideas, new conception that are combined with traditional techniques to reflect the taste-oriented design style and quality of Foshan ceramic doll art in the new era and thus provide impetus for the further development of 
Foshan ceramic doll art.

As a kind of national and cultural carrier, Foshan ceramic doll art embodies all kinds of life and culture closely related to the masses. The inheritance and development of this intangible cultural heritage is based on the efforts of ceramic artists and Foshan people engaged in ceramic doll art research. Like other types of Chinese culture, Shiwan's ceramic doll art has never been interrupted in the long history of development. This also fully reflects the historical inheritance of the splendid culture of the Chinese nation and the great role of the cohesion of the Chinese nation. The design research of ceramic doll art in Shiwan of Foshan is not only related to ceramic designer in Shiwan, but also carries the dream of the development of intangible culture in whole Guangdong province. At the same time, it is also one of the manifestations of Chinese Dream. As part of the study of Lingnan culture, the research on the taste-oriented design of Foshan ceramic dolls has enrich new contents and opened up a new realm to the study of Lingnan culture, which is also of great significance for inheriting and developing our traditional national skills, inheriting and carrying forward Lingnan culture and enhancing the soft power of Guangdong culture. 